\title{
Continual in situ monitoring of pore water stable isotopes in the subsurface
}

\author{
T. H. M. Volkmann and M. Weiler
}

Chair of Hydrology, Faculty of Environment and Natural Resources, University of Freiburg, Fahnenbergplatz, 79098 Freiburg, Germany

Correspondence to: T. H. M. Volkmann (till.volkmann@hydrology.uni-freiburg.de)

Received: 13 September 2013 - Published in Hydrol. Earth Syst. Sci. Discuss.: 5 November 2013

Revised: 10 March 2014 - Accepted: 12 March 2014 - Published: 20 May 2014

\begin{abstract}
Stable isotope signatures provide an integral fingerprint of origin, flow paths, transport processes, and residence times of water in the environment. However, the full potential of stable isotopes to quantitatively characterize subsurface water dynamics is yet unfolded due to the difficulty in obtaining extensive, detailed, and repeated measurements of pore water in the unsaturated and saturated zone. This paper presents a functional and cost-efficient system for nondestructive continual in situ monitoring of pore water stable isotope signatures with high resolution. Automatic controllable valve arrays are used to continuously extract diluted water vapor in soil air via a branching network of small microporous probes into a commercial laser-based isotope analyzer. Normalized liquid-phase isotope signatures are then obtained based on a specific on-site calibration approach along with basic corrections for instrument bias and temperature dependent isotopic fractionation. The system was applied to sample depth profiles on three experimental plots with varied vegetation cover in southwest Germany. Two methods (i.e., based on advective versus diffusive vapor extraction) and two modes of sampling (i.e., using multiple permanently installed probes versus a single repeatedly inserted probe) were tested and compared. The results show that the isotope distribution along natural profiles could be resolved with sufficiently high accuracy and precision at sampling intervals of less than four minutes. The presented in situ approaches may thereby be used interchangeably with each other and with concurrent laboratory-based direct equilibration measurements of destructively collected samples. It is thus found that the introduced sampling techniques provide powerful tools towards a detailed quantitative understanding of dynamic and heterogeneous shallow subsurface and vadose zone processes.
\end{abstract}

\section{Introduction}

Stable isotope ratios of hydrogen $\left({ }^{2} \mathrm{H} /{ }^{1} \mathrm{H}\right)$ and oxygen $\left({ }^{18} \mathrm{O} /{ }^{16} \mathrm{O}\right)$ provide powerful tracers of water in the hydrologic cycle (Gat, 1996). This is due to the conservative nature of the stable isotopes as an intrinsic part of the water molecule and the measurable variations of their ratios in precipitated and other natural waters imposed by large and variable fractionations during physicochemical processes and reactions such as, and most importantly, phase changes (Craig, 1961; Dansgaard, 1964; Friedman et al., 1964; Ehhalt and Knott, 1965; Majoube, 1971). The isotopic distinctness of input waters to a system in space and time provides for a continuously and naturally imprinted signature that can be traced to reveal information on transit times, origin, flow pathways, and processes such as phase transitions, transport, and exchange.

As such, the analysis of stable water isotopes is being widely employed in hydrology and related disciplines and has brought major advances to our understanding of natural systems (see reviews by Ehleringer and Dawson, 1992; Kendall and McDonnell, 1998; Yakir and Sternberg, 2000; Vitvar et al., 2005; Aggarwal et al., 2007; West et al., 2010b; Soderberg et al., 2012). In particular, stable isotope signatures of pore water have provided insight into soil evaporation (Zimmermann et al., 1967; Allison, 1982; Allison et al., 1983; Barnes and Allison, 1988; Walker et al., 1988); recharge rates (Dincer et al., 1974; Saxena, 1984; Darling and Bath, 1988); unsaturated and saturated subsurface flow processes, mixing, and residence times (Sklash and Farvolden, 1979; Buttle and Sami, 1990; McDonnell, 1990; Stewart and McDonnell, 1991; Gazis and Feng, 2004; Laudon et al., 2004; Garvelmann et al., 2012); 
evapotranspiration partitioning (Hsieh et al., 1998a; Wang and Yakir, 2000; Yepez et al., 2005; Rothfuss et al., 2010); hydraulic lift (Dawson, 1993, 1996; Schulze et al., 1998); and sources of plant water uptake (White et al., 1985; Dawson and Ehleringer, 1991; Walker and Richardson, 1991; Thorburn et al., 1992).

However, the full potential of stable water isotopes to quantitatively characterize water dynamics is yet to be unfolded. This particularly holds with regard to complex and heterogeneous processes, such as infiltration and shallow subsurface flow in the vadose zone subject to strong gradients and fluxes of energy and matter, demanding stable isotope data with high spatial and temporal resolution to complement traditional observations. Instead, a major limitation to the extent and scope of stable isotope applications was imposed by the available techniques for sampling and analysis (e.g., Kerstel and Meijer, 2005; Helliker and Noone, 2010; Munksgaard et al., 2011). Conventionally, measurement of water stable isotopic composition was relatively labor-, time-, and cost-intensive and constrained to laboratory-bound analysis of previously collected and processed discrete samples based on gas source isotope ratio mass spectrometry (IRMS) (Horita and Kendall, 2004). Pore water samples were most commonly obtained through destructive collection of geologic material and subsequent extraction using various methods (e.g., Buttle and Sami, 1990; Ingraham and Shadel, 1992; Walker et al., 1994; West et al., 2006) or, less frequently, using suction or gravity lysimeters (e.g., Stewart and McDonnell, 1991; Wels et al., 1991; Landon et al., 1999; Figueroa-Johnson et al., 2007). Each method is, however, associated with considerable uncertainty and unclear implications for the representativeness of obtained pore water isotopic signatures.

In recent years, major advances in analyzing techniques have come with the advent of commercially available, portable, and field-deployable laser spectroscopic instruments for isotopic analysis of water vapor (see reviews by Kerstel and Meijer, 2005; Kerstel and Gianfrani, 2008; Helliker and Noone, 2010). Available instruments based on, for instance, wavelength-scanned cavity ring-down spectroscopy (WS-CRDS) allow for direct simultaneous highfrequency measurements of oxygen and hydrogen stable isotopic composition of water vapor at a precision and accuracy approaching that of IRMS (Berden et al., 2000; Crosson, 2008; Kerstel and Gianfrani, 2008; Gupta et al., 2009). Such isotope analyzers promote broader usage of stable isotope analysis by allowing measurement of collected liquid and vapor phase samples with minimal or no preparation, higher throughput rates, and lower cost (Gupta et al., 2009).

In addition, current instruments facilitate direct continuous in situ monitoring of stable isotopes in, for example, atmospheric moisture (e.g., Gupta et al., 2009; Iannone et al., 2010; Sturm and Knohl, 2010; Johnson et al., 2011; Aemisegger et al., 2012). Other recent studies have used WSCRDS for continuous determination of liquid water isotopic composition in laboratory experiments (Munksgaard et al., 2011; Herbstritt et al., 2012) and field applications (Munksgaard et al., 2012a, b) by direct intake and analysis of vapor diffused into a dry gas stream via a submerged semipermeable membrane body. A similar direct equilibration methodology can also be applied to determine the isotope signature of liquid pore water in situ as recently shown by Rothfuss et al. (2013) in a sand beaker laboratory experiment. In fact, the feasibility of inferring the stable isotopic composition of soil water by in situ extraction of water vapor or carbon dioxide $\left(\mathrm{CO}_{2}\right)$ from soil air has already been indicated by Thoma et al. (1979) and Allison et al. (1987), while more recently IRMS and laser spectroscopic instruments have been applied to analyze pore water in destructively collected geologic material by headspace sampling of equilibrated water vapor and $\mathrm{CO}_{2}$ (Hsieh et al., 1998b; Koehler et al., 2000; Wassenaar et al., 2008; Garvelmann et al., 2012).

Building upon the previous work, this paper presents the development and application of a novel field system for continual unattended in situ monitoring of liquid pore water stable isotopes by delivering diluted soil water vapor via small microporous soil water isotope probes (SWIPs) from an arbitrary number of subsurface sources into a commercial WSCRDS instrument. Representing a trade-off between expenditure and universality in application, two different implementations of the monitoring system are investigated. These are henceforth referred to as the advection dilution sampling (ADS) method and the diffusion dilution sampling (DDS) method, according to the respective dominant vapor transport mechanism across the microporous probing tube (as in Munksgaard et al., 2011). The aim was to develop a functional system suitable for monitoring dynamic and heterogeneous subsurface processes at the relevant temporal and spatial scales. The system shall therefore facilitate accurate and precise in situ measurements while meeting the following desirable attributes:

- inexpensive in terms of both acquisition and maintenance and expandable to a large number of probing locations as prerequisite to broad and locally dense application and thus, high spatial resolution;

- short sampling interval to facilitate frequent measurements and thus, high temporal resolution;

- unattended applicability under most conditions encountered in the subsurface throughout the day and year as a prerequisite for continuous observations;

- compact (subsurface components), easy and quick to install imposing little disturbance and obstruction to the natural subsurface system and processes under investigation; 


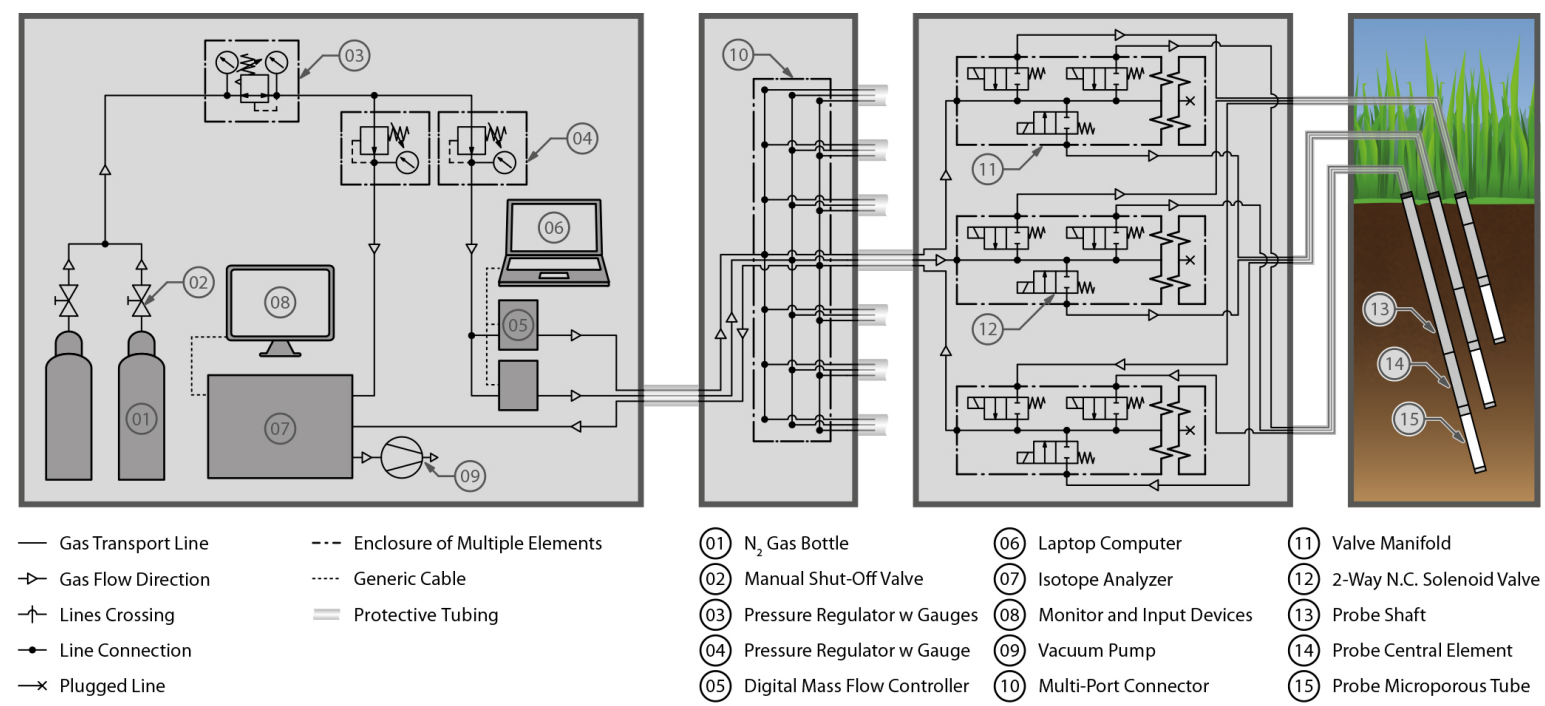

Figure 1. Schematic representation of the in situ pore water stable isotope monitoring system setup according to the DDS method.

- mechanically robust and largely chemically inert, weathering resistant components to facilitate safe insertion and prolonged duration in natural subsurface environments.

\section{Methods}

In this section, the basic setup, working principle, operation, and data processing of the monitoring system are first described, followed by the field evaluation approach. Throughout this paper, the $\delta$-notation (e.g., $\delta^{18} \mathrm{O}$ or $\delta^{2} \mathrm{H}$ ) is used to express the isotopic composition of a sample in units of parts per thousand $(\% o)$. For a given element (e.g., $\mathrm{O}$ or $\mathrm{H})$, this is defined as

$\delta=\left(\frac{R_{\text {sample }}}{R_{\text {reference }}}-1\right) \cdot 1000 \%$,

where $R_{\text {sample }}$ denotes the atomic ratio of a rare to the most abundant isotope of this element (e.g., ${ }^{18} \mathrm{O} /{ }^{16} \mathrm{O}$ or $\left.{ }^{2} \mathrm{H} /{ }^{1} \mathrm{H}\right)$ in a sample, and $R_{\text {reference }}$ is the same ratio of the employed international reference standard, Vienna Standard Mean Ocean Water (VSMOW). Subscripts "l" and "v" are used to indicate reference to liquid and vapor phase water isotopic composition, respectively.

\subsection{In situ monitoring system}

\subsubsection{Monitoring system setup}

A schematic representation of the monitoring system setup is provided in Fig. 1. All components were selected in compliance with the above stated desirable attributes. The system is builtup modularly and can simply be modified or augmented to accommodate a certain number of probes with relatively little extra cost. A single set of central analyzing and supply devices is sufficient to operate a multitude of SWIP sampling locations via a branching tubing network and valve control system. A commercial laser spectroscopic instrument (Picarro L2120-i WS-CRDS, Santa Clara, CA, USA) is used, analyzing an air stream drawn through the attached main sample line by a downstream vacuum pump for $\delta^{18} \mathrm{O}_{v}, \delta^{2} \mathrm{H}_{\mathrm{v}}$, and vapor concentration at a frequency of $0.5 \mathrm{~Hz}$. Further, a nitrogen gas $\left(\mathrm{N}_{2}\right)$ supply installation is employed, comprising a regulated pressurized source to the main dilution line with a flow rate adjustable to a target value sequence imposed by a programmable digital mass flow controller (AnalytMTC, Müllheim, Germany). In case of the diffusion dilution sampling (DDS) method, the $\mathrm{N}_{2}$ supply is split upstream of the first mass flow controller and a second mass flow controller is used to regulate the flow rate through the main throughflow line. The CRDS instrument and $\mathrm{N}_{2}$ supply installations are housed in a customized trailer for field deployment. The trailer comprises a voltage transformer and high capacity accumulators to enable stable and gap-free operation using an electric generator power source in remote field applications and is vented to prevent instrument overheating.

Each of the main gas transport lines is branched in two steps to facilitate operation of a multitude of probes at varying locations with minimum total tubing length. The main gas transport lines are guided from the trailer to a central distribution box where radial multi-port connectors (Upchurch Scientific, Oak Harbor, WA, USA) are used to distribute the main lines towards local control boxes associated with a cluster of probes installed in the subsurface (e.g., at varying depths beneath a specific surface location). Arrays of two-way normally closed electromechanically actuated solenoid valves (Clippard Minimatic, Cincinnati, OH, USA) mounted on manifold blocks (custom manufactured from polyvinylidene fluoride (PVDF) by Fischer Plastics, 


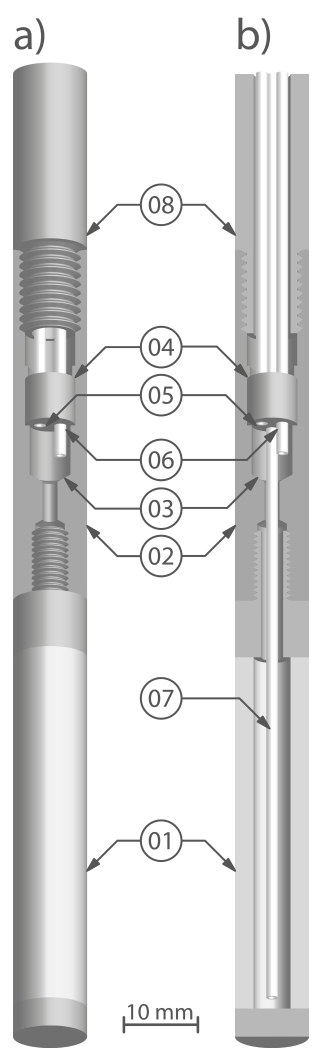

Figure 2. Schematic three-dimensional representation of the in situ soil water isotope probes according to (a) the ADS and (b) the DDS method. Labels indicate (1) microporous tube, (2) central element, (3) mixing chamber, (4) line retainer, (5) sample line, (6) dilution line, (7) throughflow line, and (8) insertion and protection shaft.

Gundelfingen, Germany) are used to further split and control the incoming gas transport lines towards individual probes. The valves are actuated either manually or automatically by a microcontroller switching unit. Valves controlling the ports receiving gas transport lines of a specific probe on each manifold are coupled and operated simultaneously.

All tubing used for the monitoring system gas transport lines consists of fluorinated ethylene propylene (FEP) and is protected by mesh hoses. All sample lines and all lines immediately attached to the probes have an inner diameter (ID) of $1 \mathrm{~mm}$, while the remaining $\mathrm{N}_{2}$ supply lines have an ID of $1 / 16 \mathrm{in}$. The total effective length of each gas transport line (from each probe to each end device) depends on the study design and field situation and amounted to ca. $10 \mathrm{~m}$ in the present study. Outside the trailer, all tubing connections can quickly and without tools be finger tightened using removable and reusable fittings (Upchurch Scientific), while stainless steel fittings (Swagelok, Solon, OH, USA) are used inside the trailer.

Each soil water isotope probe (Fig. 2) is composed of three major custom parts connectable via threads. The core of the probe is a rigid hydrophobic microporous polyethylene (PE) probing tube (Porex Technologies, Aachen, Germany) with a length of $50 \mathrm{~mm}$ and an outer diameter (OD) of $10 \mathrm{~mm}$. The hydrophobic material allows water vapor contained in the soil air to pass while prohibiting liquid water penetration at sufficiently low differential pressures. The microporous tube is sealed on one end and connected on the other end to a central element manufactured from PVDF (Fischer Plastics). The central element contains a mixing chamber and accepts a line retainer with two (ADS; Fig. 2a) or three (DDS; Fig. 2b) gas transport lines attached. The central element can be connected to a rigid insertion shaft of variable length (here, 100 to $700 \mathrm{~mm}$ ) made of anodized aluminum, guiding and protecting the gas transport lines in the subsurface. This design facilitates convenient probe installation from the soil surface with little disturbance of the subsurface environment. The probes are installed into pre-drilled holes using a steel tube with an OD of $10 \mathrm{~mm}$, thus favoring immediate close contact of the subsequently inserted probes with and preventing compaction of the surrounding soil matrix.

The system can be used to sample the distribution of pore water stable isotopic composition in two different modes. On the one hand, a multitude of soil probes can be permanently installed in clusters to continually monitor, for example, depth profiles below various surface locations (i.e., continual mode). On the other hand, a single probe can be used to subsequently sample spatial distributions by repeated insertion at various locations and depths (i.e., push-in mode). Of course, continuous sampling using a single permanently installed probe is also possible; however, this will seldom present a relevant mode of field application.

A specific calibration approach following the principle of identical treatment is used to facilitate normalization of measured isotope signatures to the VSMOW reference scale. Therefore, four polyvinyl chloride (PVC) boxes of size $20 \mathrm{~cm} \times 30 \mathrm{~cm} \times 30 \mathrm{~cm}$ were equipped with a centrally placed SWIP, closely neighbored by two 5TE probes and one MPS-1 probe (both Decagon Devices, Pullman, WA, USA) sensing soil water content, temperature, electrical conductivity, and matric potential. The boxes were then filled with oven-dried soil material from the upper $60 \mathrm{~cm}$ of the study site. Subsequently, water of known isotopic composition was added to generate a soil water content of ca. $20 \mathrm{vol} \%$ at the depth of the probes and the boxes were immediately sealed. The waters used included an isotopically light and a heavy laboratory standard serving for normalization during calibration and an intermediate laboratory standard used twice (i.e., for two boxes) and serving for quality control. The respective boxes are henceforth referred to as calibration and control standard boxes. During field sampling, three of the boxes were placed into a thermo-insulated housing to reduce temperature variations, while one control standard box was placed outside the housing, thus being subject to stronger temperature variations. The initial setup of the boxes requires approximately two hours of work and less than USD 100 of monetary effort (excluding soil physical and 
soil water isotope probes). Preparation for a specific application requires approximately three hours of work (excluding collection of soil material).

\subsubsection{Monitoring system operation}

An individual probe is operated by simultaneously opening the associated valve on each of the manifolds, while all other valves are closed. Once the valves are open, sample air is drawn through the sample line at a rate of $30-35 \mathrm{~mL} \mathrm{~min}^{-1}$ imposed by the vacuum pump of the CRDS instrument. At the same time, $\mathrm{N}_{2}$ is supplied via the dilution line into the mixing chamber with a controllable rate. If the $\mathrm{N}_{2}$ supply rate is lower than the sample intake rate, soil air saturated with water vapor at the local temperature advects through the walls of the microporous probing tube in response to the applied absolute pressure gradient. The soil air flows into the mixing chamber, where it is diluted to a lower vapor concentration as determined by the ratio of $\mathrm{N}_{2}$ supply rate to sample intake rate. This diluted vapor-sample stream enters the sample line and flows to the CRDS instrument (ADS method). By varying the $\mathrm{N}_{2}$ supply rate, the vapor mixing ratio can be controlled from close to zero to saturation at soil source temperature. The primary purpose of the vapor dilution is to preclude any condensation of water due to varying temperature along the sample line while avoiding a sample line heating system.

In case of the DDS method, an additional third gas transport line (throughflow line) supplies $\mathrm{N}_{2}$ to the lower end of the probe. The rate is regulated by a second mass flow controller to equal the difference between sample intake rate and dilution rate, such that no absolute pressure gradients result across the microporous wall. Instead, driven by a partial pressure gradient, vapor diffuses into the probing tube to saturate the through flowing $\mathrm{N}_{2}$ carrier gas. As for the ADS method, the sample stream is transported to the analyzer and diluted in the process. While this method raises the expenses for monitoring system acquisition and operation, it provides the advantage that it can be applied under saturated conditions as long as the water entry pressure of the employed microporous material is not exceeded.

The monitoring system allows for manual or automated sampling using programmed probe and dilution rate sequences. In a typical probe sequence, all SWIPs are subsequently sampled, moving from one cluster to the next, occasionally intermitted by sampling the standard boxes. A given location is typically probed using a dilution rate sequence starting with a short flushing phase with high dilution, thus clearing the mixing chamber, sample lines, and cavity (i.e., the entire path for the new sample vapor) from vapor of previous samples. This is followed by a sampling phase with lower dilution. In the present application, each in situ measurement was conducted using a sequence of $60 \mathrm{~s}$ flushing and $150 \mathrm{~s}$ sampling. Thereby, dilution flow rates of 36 and $18 \mathrm{~mL} \mathrm{~min}^{-1}$ were used, respectively. The former
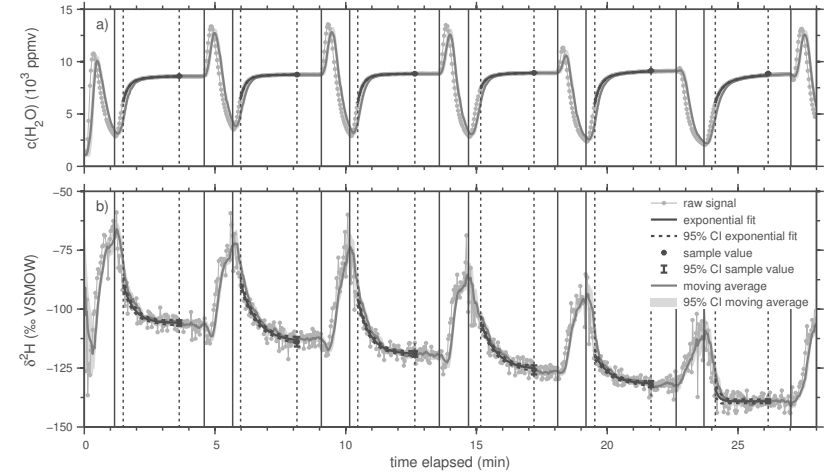

Figure 3. Exemplary time series signal representing the acquisition of a pore water stable isotope profile using the in situ sampling system with permanently installed ADS probes and a dilution sequence of $60 \mathrm{~s}$ flushing and $210 \mathrm{~s}$ sampling. Solid vertical lines enclose periods of sample arrival. Exponential fits use data from the asymptotic period up to $150 \mathrm{~s}$ after start of sample arrival, as enclosed by the dashed vertical lines. A moving average ( $15 \mathrm{~s}$ backward) is provided for illustrative purposes.

slightly exceeds the nominal sample intake rate, while the latter presents the minimal dilution rate necessary to avoid condensation during $>95 \%$ of the time of a day and year in the region of application, as computed from multi-year temperature records.

\subsubsection{Signal processing}

Processing of the acquired time series signals is fully automated into a MATLAB ${ }^{\circledR}$ (The MathWorks, Inc., Natick, MA, USA) toolbox. Standard processing for the CRDSbased measurements includes derivation of raw sample values from the observed high-frequency signals, subsequent corrections to account for instrument-specific vapor concentration biases, drift, and deviations from the internationally accepted reference scale (e.g., Schmidt et al., 2010; Sturm and Knohl, 2010; Gröning, 2011; Aemisegger et al., 2012), as well as conversion of the corrected vapor to respective liquid water isotopic compositions.

Inspecting the acquired time series of water vapor concentration (Fig. 3a), individual sample phases can be easily identified as step input responses with a vapor concentration asymptotically approaching a level depending on the soil temperature and the imposed dilution rate. The asymptotic behavior can be primarily attributed to advective-diffusivereactive transport through the soil pore space and the various segments of the probing system as well as storage effects such as cavity reservoir gas exchange. The preceding flush phase is characterized by an initial peak followed by declining vapor concentration, emptying the sample line for the next sample intake. Note also that a short time lag (ca. 20s) exists between observed responses and switching 
of valves and dilution rates due to the bulk transport through the sample lines.

To determine the vapor concentration and raw isotopic composition of each sample, the acquired time series of vapor concentration is first scanned to identify characteristic times based on differentiation of the signal (i.e., using a multi-point moving slope to reduce the impact of noise). These include the defined start time of sample arrival, start time of asymptotic behavior, and end time of sample arrival, which are identified as the stationary point, first inflection point (from convex to concave downwards), and second inflection point (from concave to convex downwards) following a declining flush phase, respectively. Second, sample values are obtained as steady-state solution of a simple exponential function fitted to the respective asymptotic period of sample arrival in a least squares sense. Using the root mean squared error (RMSE) as quality criterion, it was found that exponential models of type

$\delta(t)=\delta_{\infty}+\left(\delta_{0}-\delta_{\infty}\right) e^{(-t / \tau)}$,

where $t$ indicates the time, $\tau$ is a time constant, and subscripts 0 and $\infty$ indicate the initial and steady-state solution, respectively, fit well (RMSE $<0.4 \%$ for $\delta^{18} \mathrm{O}_{\mathrm{v}}$ and $<3.3 \%$ o for $\delta^{2} \mathrm{H}_{\mathrm{v}}$ ) to the observed $\delta$-value response signal. Further, exponential models of type

$c(t)=c_{\infty}+\left(c_{0}-c_{\infty}\right) e^{\left(-t / \tau_{1}\right)}+\lambda e^{\left(-t / \tau_{2}\right)}$,

where $\tau_{1}$ and $\tau_{2}$ are time constants and $\lambda$ is a parameter, fit well (RMSE $<80 \mathrm{ppmv}$ ) to the observed vapor concentration $c$ response signal. Note that device related corrections (e.g., vapor concentration dependency) may be applied prior to fitting a model in case they are non-linear. The $95 \%$ confidence interval (CI) of the exponential model fits is computed based on the estimated coefficient covariance matrix (on average $0.19 \%$ for $\delta^{18} \mathrm{O}_{\mathrm{v}}, 1.5 \%$ for $\delta^{2} \mathrm{H}_{\mathrm{v}}$, and $11 \mathrm{ppmv}$ for $c$ ) and illustrates the uncertainty of sample value estimation from the signal (Fig. 3). While some average value over a specified segment of the asymptotic period could actually be used without significant deterioration of data quality, the asymptotic model makes better use of the data, can reduce the impact of noise and increase the precision, is independent of an averaging interval, less dependent on the selected period, and provides for a statistically more valid approach. These aspects are of particular relevance when short sampling times are targeted. However, we omit fitting a more complex model to the entire response signal at this point, partially to avoid the impact of noisy observations at low vapor concentration.

The obtained raw sample values of $\delta^{18} \mathrm{O}_{\mathrm{v}}$ and $\delta^{2} \mathrm{H}_{\mathrm{v}}$ are then corrected for analyzer specific vapor concentration dependent bias relative to an arbitrary reference concentration. Least-squares-fitted relations were derived prior to the field sampling based on vaporized discrete laboratory standard water aliquots of three isotopic compositions and varying volume. The aliquots were injected into a vaporizer using a liquid auto sampler and $\mathrm{N}_{2}$ was used as a carrier gas.
The sample liquid water isotopic composition (i.e., $\delta^{18} \mathrm{O}_{1}$ and $\left.\delta^{2} \mathrm{H}_{1}\right)$ associated with each $\delta^{18} \mathrm{O}_{\mathrm{v}}$ and $\delta^{2} \mathrm{H}_{\mathrm{v}}$ value is then estimated using soil temperatures measured at the respective depth of vapor extraction along with the equations for free water liquid-vapor equilibrium fractionation established by Majoube (1971). Finally, a combined calibration and drift correction is applied for normalization of $\delta^{18} \mathrm{O}_{1}$ and $\delta^{2} \mathrm{H}_{1}$ values to the VSMOW reference scale and elimination of temporal biases. Therefore, calibration standard measurements obtained approximately every two to three hours and processed identically to in-soil measurements up to this point are linearly interpolated to the time of each other sample to conduct a linear two-point calibration (e.g., Gröning, 2011).

\subsection{Field application and evaluation}

\subsubsection{Site description and instrumentation}

The in situ monitoring system was tested under field conditions and evaluated against results from concurrent destructive sampling. Measurements were conducted during one day in September 2012 on an experimental site located at $310 \mathrm{~m}$ above sea level on a vineyard terrace of the Kaiserstuhl mountain range $\left(48^{\circ} 05^{\prime} 33.48^{\prime \prime} \mathrm{N}, 7^{\circ} 42^{\prime} 24.06^{\prime \prime} \mathrm{E}\right)$ in southwest Germany. The mean annual temperature is $11^{\circ} \mathrm{C}$ and the mean annual precipitation amounts to $900 \mathrm{~mm}$. A local meteoric water line (LMWL) was obtained based on weekly bulk samples of precipitation collected on the site from June 2011 to August 2012. The slightly clayey silt soils (Calcaric Regosol) of the study site developed from a thick layer of Pleistocene aeolian loess covering the Tertiary volcanic rock forming the Kaiserstuhl (Hädrich and Stahr, $2001)$. Due to the low slope $(<5 \%)$ and deep permeable soils, water fluxes are predominantly vertical.

Plots of size $3 \mathrm{~m}^{2}$ were instrumented and planted with various species in 2011 as part of ongoing research. 5TE and MPS-1 or MPS- 2 probes installed at depths of $5,10,20, \ldots$, $60 \mathrm{~cm}$ deliver data at $10 \mathrm{~min}$ intervals. Three plots planted with grass, beech, and no vegetation (i.e., bare soil) were selected for this study. The plots had been sheltered from precipitation approximately two weeks prior to sampling such that quasi-static conditions in terms of pore water content and isotopic composition may be assumed.

\subsubsection{Destructive pore water isotope sampling}

For each plot, three soil cores were retrieved using a Pürckhauer drill. The cores were immediately partitioned into samples representing depth intervals of $0-5,5-15, \ldots, 75-$ $85 \mathrm{~cm}$ and stored into gas-impermeable bags (Weber Packaging, Güglingen, Germany). The bags were subsequently filled with $\mathrm{N}_{2}$, heat-sealed, and analyzed in the laboratory using the direct equilibration method as detailed by Wassenaar et al. (2008) and Garvelmann et al. (2012). The headspace water vapor isotopic composition of each sample was probed 
Table 1. Summary statistics of in situ and destructive laboratory-based pore water stable isotope measurements of quality control standards with and without thermo-insulation (TI) and soil profiles.

\begin{tabular}{|c|c|c|c|c|c|c|c|c|c|}
\hline & & \multicolumn{4}{|c|}{ ADS } & \multicolumn{3}{|c|}{ DDS } & \multirow{3}{*}{$\begin{array}{c}\text { Destructive } \\
\text { Control }\end{array}$} \\
\hline & & \multicolumn{2}{|c|}{ Control } & \multicolumn{2}{|c|}{ Soil } & \multicolumn{2}{|c|}{ Control } & \multirow{2}{*}{$\begin{array}{c}\text { Soil } \\
\text { Push-in }\end{array}$} & \\
\hline & & w/ TI & w/o TI & Installed & Push-in & w/ TI & w/o TI & & \\
\hline \multirow{6}{*}{$\delta^{18} \mathrm{O}_{1}(\% o)$} & RMSE & 0.16 & 0.17 & 0.38 & 0.43 & 0.15 & 0.18 & 0.42 & 0.15 \\
\hline & MAE & 0.13 & 0.14 & 0.31 & 0.35 & 0.12 & 0.14 & 0.34 & 0.11 \\
\hline & BIAS & -0.02 & 0.02 & 0.04 & -0.02 & -0.02 & 0.03 & -0.04 & -0.01 \\
\hline & SD & 0.16 & 0.17 & 0.37 & 0.43 & 0.15 & 0.18 & 0.42 & 0.15 \\
\hline & LOA upper & 0.29 & 0.35 & 0.77 & 0.82 & 0.27 & 0.38 & 0.78 & 0.28 \\
\hline & LOA lower & -0.33 & -0.31 & -0.69 & -0.86 & -0.31 & -0.32 & -0.86 & -0.30 \\
\hline \multirow{6}{*}{$\delta^{2} \mathrm{H}_{1}(\% o)$} & RMSE & 1.23 & 1.15 & 2.87 & 2.92 & 1.32 & 1.20 & 3.09 & 1.03 \\
\hline & MAE & 1.05 & 0.98 & 2.38 & 2.35 & 1.10 & 1.02 & 2.53 & 0.86 \\
\hline & BIAS & -0.12 & 0.10 & 0.32 & -0.20 & -0.17 & 0.12 & -0.37 & -0.10 \\
\hline & SD & 1.22 & 1.15 & 2.85 & 2.91 & 1.32 & 1.20 & 3.06 & 1.03 \\
\hline & LOA upper & 2.27 & 2.35 & 5.91 & 5.50 & 2.42 & 2.47 & 5.63 & 1.92 \\
\hline & LOA lower & -2.51 & -2.15 & -5.27 & -5.90 & -2.76 & -2.23 & -6.37 & -2.12 \\
\hline$T^{\mathrm{a}}\left({ }^{\circ} \mathrm{C}\right)$ & Min/max & $13 / 21$ & $11 / 23$ & $14 / 19$ & $14 / 19$ & $14 / 19$ & $12 / 22$ & $14 / 19$ & $21 / 22$ \\
\hline$c^{\mathrm{b}}\left(10^{3} \mathrm{ppmv}\right)$ & Min/max & $7 / 13$ & $6 / 14$ & $7 / 10$ & $7 / 10$ & $7 / 10$ & $6 / 13$ & $7 / 10$ & $26 / 27$ \\
\hline$n^{\mathrm{c}}$ & & 18 & 18 & 36 & 36 & 9 & 9 & 36 & 9 \\
\hline
\end{tabular}

${ }^{\text {a }}$ Temperature; ${ }^{\mathrm{b}}$ Vapor concentration; ${ }^{\mathrm{c}}$ Sample size.

for $390 \mathrm{~s}$ at constant temperature using the same WS-CRDS analyzer as above. Raw sample $\delta^{18} \mathrm{O}_{\mathrm{v}}$ and $\delta^{2} \mathrm{H}_{\mathrm{v}}$ values were obtained as the arithmetic mean over the last $90 \mathrm{~s}$ of sample arrival and consequently normalized, drift corrected, and converted to $\delta^{18} \mathrm{O}_{1}$ and $\delta^{2} \mathrm{H}_{1}$ values as described for the in situ sampling. Following a similar identical treatment approach, calibration and quality control were conducted based on reference samples prepared from oven-dried soil material from the study site mixed with three laboratory standard waters. The reference samples were prepared to have the same dry mass as the average soil samples and a water content of $20 \mathrm{vol} \%$, otherwise treated identically to the soil core samples, and alternatingly analyzed between groups of three soil core samples.

\subsubsection{In situ pore water isotope sampling and evaluation}

Three in situ sampling approaches were selected, each to obtain two pore water isotope profiles for each plot with discrete measurements at depths of $10,20, \ldots, 60 \mathrm{~cm}$. In situ measurements were conducted and processed as described above and using (i) a subset of 18 ADS probes permanently installed at the respective locations and depths in July 2012 as part of ongoing research, (ii) an ADS probe in push-in mode (i.e., subsequently inserted at the respective locations and depths), and (iii) a DDS probe in push-in mode.
The methodological accuracy of and the agreement between processed in situ and destructive laboratory-based isotope measurements are assessed in terms of the differences to known control standard values and to each other (i.e., evaluating all measurements from equal depths and similar vegetation cover against each other), respectively. Summary statistics provided include the respective root mean squared differences (RMSE), mean absolute differences (MAE), mean differences (BIAS), and $95 \%$ limits of agreement (LOA) estimated as the BIAS \pm 1.96 -fold standard deviation (SD) of the differences (Bland and Altman, 1986). For each method, the methodological precision and the reproducibility (or variability) of soil profile measurements are assessed in terms of the (pooled) SD of processed control standard measurements and repeated soil measurements at equal depths, respectively. Control standards placed inside and outside a thermo-insulated housing are evaluated separately to assess the impact of larger temperature and associated vapor concentration variations and differences to calibration conditions. In addition to data obtained during the day of profile sampling, a multi-day record of control standard measurements obtained as part of ongoing research is used to increase the sample size. 


\section{Results}

\subsection{Evaluation of sampling methods}

The monitoring system facilitates rapid signal stabilization enabling high-quality sample value estimates at short sampling intervals for the employed dilution sequence and under the field conditions encountered (Table 1; Fig. 3). The time required to reach a stable signal depends upon a variety of operational and environmental factors, such as dilution sequence and rates or magnitude of isotopic differences between successive samples. While a systematic assessment is beyond the scope of this paper and sample value estimation was based on exponential models, it is noted that time constants for exponential fits to the asymptotic periods of the acquired signals, starting ca. $18 \pm 4 \mathrm{~s}$ (arithmetic mean $\pm \mathrm{SD}$ ) after first sample arrival, were similar for all in situ sampling approaches and averaged to ca. $31 \pm 12 \mathrm{~s}$ for $\delta^{18} \mathrm{O}_{\mathrm{v}}$ and $34 \pm 13 \mathrm{~s}$ for $\delta^{2} \mathrm{H}_{\mathrm{v}}$. This given, the time required for the signal to approach a steady value to within a range of, e.g., $\pm 0.1 \%$ for $\delta^{18} \mathrm{O}_{\mathrm{v}}$ and $\pm 0.5 \%$ o for $\delta^{2} \mathrm{H}_{\mathrm{v}}$, which corresponds to half the analyzer precision specification (Picarro, 2012), can be estimated to amount $108 \pm 45 \mathrm{~s}$ for $\delta^{18} \mathrm{O}_{\mathrm{v}}$ and $128 \pm 48 \mathrm{~s}$ for $\delta^{2} \mathrm{H}_{\mathrm{v}}$. This indicates that short sampling intervals are feasible also without employing an asymptotic model.

Evaluation of control standard measurements indicates high accuracy and precision for both the ADS and the DDS method over multiple days of field operation. Summary statistics (Table 1) show that systematic errors were small, while random errors were on the order of the precision specified for the employed CRDS instrument (Picarro, 2012) and approximately twice to thrice as high as that currently attainable with IRMS instrumentation under laboratory conditions (Brand, 2004; Horita and Kendall, 2004); however, this is excluding effects related to sample collection and preparation in case of the latter, which often compromise the overall accuracy (Kerstel and Gianfrani, 2008). Thereby, larger temperature variations and deviations from calibration conditions (ca. -3 to $+4{ }^{\circ} \mathrm{C}$ ) did not significantly impact the control standard measurement error (two-sample $t$ test, $p>0.05$ ). Further, the quality of in situ measurements approached that attained for laboratory-based measurements conducted using the direct equilibration technique under constant temperature conditions and with higher vapor concentrations. Note that in case of the laboratory-based measurements, some variability may be associated with the preparation of individual reference samples for calibration and control of soil core samples in contrast to repeated in situ measurements of identical calibration and control standard boxes.

\subsection{Evaluation of soil profile measurements}

Depth profiles of pore water isotopic composition obtained based on the various in situ sampling approaches and destruc-

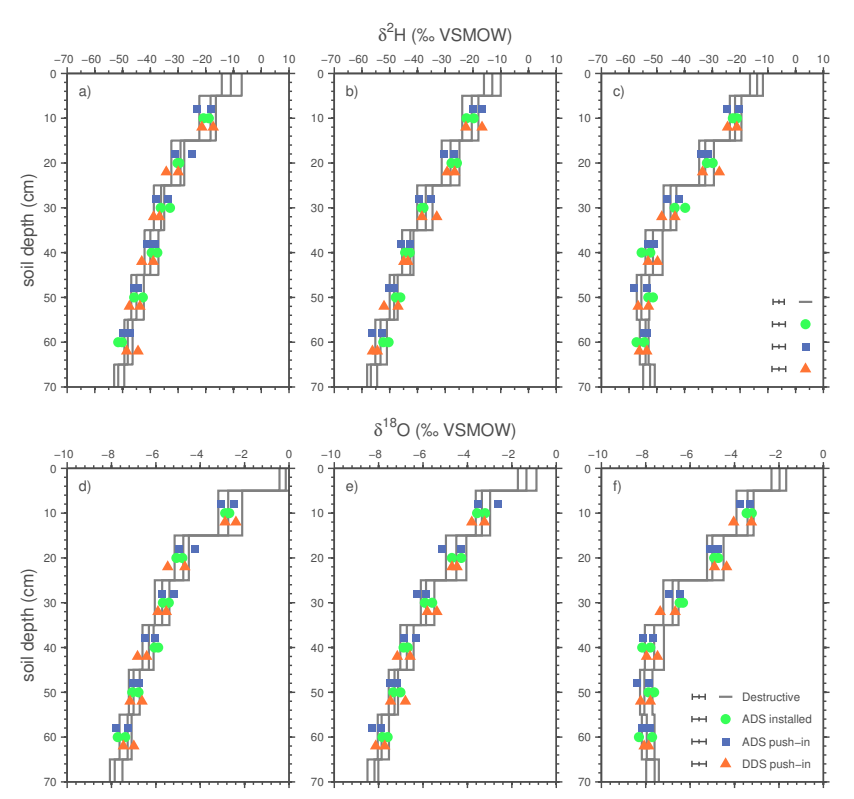

Figure 4. Depth profiles of pore water $\delta^{2} \mathrm{H}_{l}$ and $\delta^{18} \mathrm{O}_{1}$ for a bare soil $(\mathbf{a}, \mathbf{d})$, grass $(\mathbf{b}, \mathbf{e})$, and beech $(\mathbf{c}, \mathbf{f})$ plot obtained based on in situ (vertically shifted for visibility) and destructive sampling. The methodological accuracy associated with each symbol is indicated in terms of $95 \%$ limits of agreement.

tive sampling are physically plausible and generally in good agreement for all three plots under investigation (Fig. 4). This holds with respect to all, the range, distribution, and magnitude of observed isotope signatures and under the conditions encountered, with observed soil water contents and matric potentials at depths below $5 \mathrm{~cm}$ generally ranging from ca. 12 to $24 \mathrm{vol} \%$ and -150 to $-27 \mathrm{kPa}$, respectively.

Repeated in-soil measurements obtained for installed identical ADS probes coincide closely (SD $0.22 \%$ for $\delta^{18} \mathrm{O}_{1}$ and $1.6 \%$ for $\delta^{2} \mathrm{H}_{1}$ ), exhibiting a reproducibility approaching that obtained for control standard measurements and indicating the value of continual in situ multi-probe sampling. Stronger inter-profile variability exceeding the respective estimated methodological precision is observed for push-in profile sampling using the ADS (SD $0.38 \%$ for $\delta^{18} \mathrm{O}_{1}$ and $2.6 \%$ for $\delta^{2} \mathrm{H}_{1}$ ) or DDS (SD $0.37 \%$ for $\delta^{18} \mathrm{O}_{1}$ and $2.8 \%$ for $\delta^{2} \mathrm{H}_{1}$ ) probes and for destructive profile sampling (SD $0.34 \%$ for $\delta^{18} \mathrm{O}_{1}$ and $2.4 \%$ for $\delta^{2} \mathrm{H}_{1}$ ). However, this can primarily be attributed to varying target soil water isotopic composition encountered at differing sampling locations.

Comparing in situ and destructive profile sampling results, observed differences are overall similar for all in situ sampling approaches (Table 1). Comparable agreement with destructive sampling results is obtained for spatially more proximate push-in mode sampling using either method compared to continual mode sampling, supporting the assumption of sampling distance as source of intra-method variability. Similar results could be observed when comparing in situ 


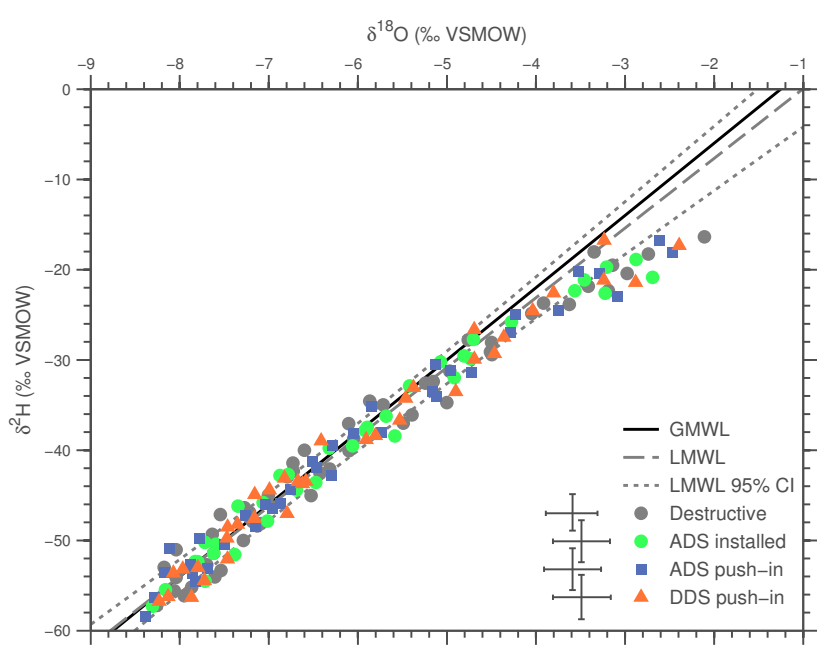

Figure 5. Plot of pore water $\delta^{2} \mathrm{H}_{1}$ versus $\delta^{18} \mathrm{O}_{1}$ obtained based on in situ and destructive sampling of soil profiles (depths from 10 to $60 \mathrm{~cm}$ ). The methodological accuracy associated with each symbol is indicated in terms of $95 \%$ limits of agreement.

sampling results obtained from different methods and modes of operation with each other (Fig. 4). In all cases, random deviations appear dominant, while biases are small. The intermethod SD and RMSE are on the order of the estimated interprofile variability for the non-continual sampling methods, indicating that intra-method variability is the major source of inter-method disagreement. Clearly, additional sources of error and uncertainty including spatial variation of targeted pore water signatures along with lack of spatial coincidence of sampling location, imprecise depth assignment, and compression during destructive sampling add to the methodological differences and errors. However, no major bias or obvious systematic dependency can be observed regarding the agreement and relative variability along the soil profiles and thus, with varying soil properties or states and gradients of soil water content, matric potential, and temperature. This indicates that any such effect, over the range of field conditions encountered and if present, does not substantially exceed the reported level of agreement or reproducibility and may thus be deemed negligible, and is at least similar for both sampling techniques, such that the methods may be used interchangeably. Further, the spatial variations in isotopic composition obtained from destructive sampling at the measurement scale of $10 \mathrm{~cm}$ are well reproduced by the in situ sampling methods, indicating that in fact a localized isotopic equilibrium between the pore water phases existed and was represented in the sampling results.

The majority of samples plot closely along the global (Craig, 1961) and local meteoric water lines (GMWL and LMWL, respectively; Fig. 5), indicating coherence of obtained $\delta^{18} \mathrm{O}_{1}$ and $\delta^{2} \mathrm{H}_{1}$ values assuming a mostly unaltered meteoric origin of waters. Only few samples, obtained in close proximity to the surface, show potentially evaporative enrichment effects. Under non-equilibrium conditions of actual net evaporation, a more complex model-based interpretation of vapor data is necessary to obtain liquid water estimates. Yet, all in situ samples displayed approximately water vapor saturation within measurement precision of spatiotemporally local temperature (i.e., based on either Kelvin or Magnus Equation and taking dilution rate into account) and agree well with headspace samples from soil cores. This may indicate that no additional net evaporation was occurring at the time of in situ sampling and further, that the effects are not related to surface proximity of sampling.

A physical interpretation of the measured isotope profiles is beyond the scope of this paper. Nevertheless, it can be noted that the last major summer rainfall reaching the ground surface had a composition of ca. $-3.5 \% \circ \delta^{18} \mathrm{O}_{1}$ and $-22 \%$ o $\delta^{2} \mathrm{H}_{1}$, while typical winter rains are at $-9.5 \%$ o $\delta^{18} \mathrm{O}_{1}$ and $-66 \% \circ \delta^{2} \mathrm{H}_{1}$. Thus, the obtained results may be deemed physically plausible and reflect the common perception of an attenuated seasonal meteoric variation subject to losses by transpiration and some evaporative enrichment in the topsoil (Dansgaard, 1964; Barnes and Allison, 1988; Garvelmann et al., 2012).

\section{Discussion}

\subsection{Monitoring system implementation and functionality}

The presented system was developed to allow for unattended functional and efficient minimal invasive field monitoring of pore water stable isotope distributions with high sampling rate and limited cost. The monitoring system is set up modularly and can be easily and flexibly installed, adapted, and extended for accommodation of a multitude of probes and changing applications with relatively little extra expenses. Automated sampling is facilitated by a microprocessor controlled switching unit with solenoid valves enduring $>10^{9}$ cycles. The rigid tubular design and small dimensions of the probes (diameter of $10 \mathrm{~mm}$ ) allow for simple installation causing little disturbance and obstruction to the subsurface flow field and processes under investigation as well as for localized vapor extraction. All parts and materials were selected to be robust and weathering resistant, allowing the system to persist in the subsurface for continuous or repeated application. Additionally, all parts that come into contact with the sample air, most importantly the FEP sample lines, have low dead volume, are chemically mostly inert, and have low water sorption, porosity, and gas permeability (e.g., Mark, 2009).

Avoiding a sample line heating approach, the in situ dilution technique provides optimal control over sample mixing ratios from the subsurface sampling location to the analyzer cavity. Adequate dilution sequences allow for efficient purging of the sample lines and clear sample detection, prevent 
condensation and associated fractionation effects at any point of the system, and potentially reduce the effects of sorption and storage in the various compartments of the monitoring system. Along with the low pumping rate, the physicochemical and isotopic disturbance of the natural soil water phase system in the probing environment (i.e., due to imposed absolute or partial pressure gradients and soil air losses) is reduced during actual and prolonged sampling.

As stated above, all in situ samples displayed approximate water vapor saturation at extraction, independent of local soil physical states or gradients. Also, clear optima of agreement between sample and saturation vapor pressures computed based on temperature measurements could be observed when considering the spatially and temporally closest observation. Further, neither repeated nor prolonged extraction (i.e., > $30 \mathrm{~min}$ ) moved the liquid-vapor system from chemical equilibrium or caused continuous modification of the observed isotopic composition. This is consistent with recent laboratory results of Rothfuss et al. (2013). Importantly, these observations imply that monitoring liquid pore water isotopic composition using the presented system does not necessarily demand actual measurements of soil temperature. Instead, the required liquid-vapor isotopic fractionation factors may be inferred based on observed vapor concentrations, provided that these are measured accurately (see e.g., Aemisegger et al., 2012), equilibrium conditions prevail, and effects of water potential are negligible or can be estimated. For the present application, very similar estimates of $\delta^{18} \mathrm{O}_{1}$ and $\delta^{2} \mathrm{H}_{1}$ could be obtained based on either measured temperatures or vapor concentrations (data not shown).

\subsection{Monitoring system performance}

The outlined technical and operational implementation is essential in practical field applications with continual accurate, precise, and rapid sampling for at least most of the year and for different climatic regions. The presented and evaluated excerpt of a field application employing a branching network of actually more than 30 SWIPs demonstrates these capabilities for the conditions encountered. A quick stabilization of the sample signal is attained, facilitating sampling intervals of approximately four minutes. Employing a specific identical treatment approach for calibration and drift correction, along with a vapor concentration bias correction and the well established formulations for free water liquid-vapor equilibrium fractionation by Majoube (1971), accurate and reproducible inference of normalized liquid pore water isotopic composition from vapor analysis was possible without specific prior characterization of additional sampling effects. Thereby, the two in situ methods tested (ADS and DDS) and the two modes of employment (continual and push-in) were shown to provide similar overall results in good agreement with laboratory-based direct equilibration measurements of destructively collected samples. The comparison of in situ and destructive sampling results, the physical plausibility and reproducibility of the measurements, and sample vapor concentrations indicate that, for the level of data quality given, the extracted vapor did in fact physicochemically and isotopically represent the spatiotemporally local liquid pore water.

The obtained precision of liquid water $\delta$-value estimates is deemed sufficient for the anticipated applications. Improvements may come from further enhanced technical and operational implementation and calibration and correction approaches. Additional measures, such as a sophisticated thermal stabilization of the isotope analyzer, may also prove necessary for continuous application across seasons and years. Longer sampling and integration times and higher vapor concentrations (i.e., lower dilution) may often reduce sampling errors and uncertainties due to proceeded signal stabilization, reduced impact of background short-term noise, and instrument precision dependencies on vapor concentration (e.g., Sturm and Knohl, 2010; Aemisegger et al., 2012), while a higher pumping rate could accelerate signal stabilization. However, the former and both must be traded off for lower sample generation rate and increased actual and long-term disturbance of the natural system, respectively. Further, it is important to note in this context that slow signal stabilization would impede proper signal attainment when the temporal scale of changes in liquid source water or of other effects on the vapor isotopic composition (e.g., temperature changes or instrument drift) is exceeded, which also limits the maximum integration time.

\subsection{Assumptions and potential limitations}

In principle, the implementation of the monitoring system allows for continuous long-term field observations with little user interaction. Primary limits on unattended application are probably imposed by the need to refresh dry gas supply and calibration standard waters. The number of samples extractable from the calibration boxes with negligible isotopic alteration depends on the initial water reservoir and the volume of liquid water lost per sample. Ca. $0.4 \mu \mathrm{L}$ of water are lost per sample (assuming $20^{\circ} \mathrm{C}$ and $1 \mathrm{~atm}$ ), resulting in $<0.2 \%$ total volume loss after $10^{4}$ calibrations for the present setup. Secondary limits derive from the life span of individual instruments (with $10^{4} \mathrm{~h}$ for the vacuum pump as likely minimum) or the probes themselves (expected several years). In remote field locations, power supply for the instruments can become the critical limiting factor. Application in a laboratory setting should, however, generally be straightforward.

Although not observed for the tested timescales, alteration of local soil water content and isotopic composition due to vapor extraction may become an issue during prolonged sampling that requires further investigation. A rough impression can be gained in this context by estimating that a single sample may reduce the water content in an isolated soil volume surrounding the probe to an arbitrary distance of $1 \mathrm{~cm}$ by $<10^{-3} \mathrm{vol} \%$ or, at a low water content of e.g., $5 \mathrm{vol} \%$, by 
$<0.02 \%$. Thus, ca. 50 repeated local measurements could be conducted before reducing even a dry moisture state by $1 \%$. Considering that small local water losses and isotopic enrichment effects are evened by flow and transport processes in the liquid and vapor phase over time, we would not expect continued alteration of local soil water once sampling intervals are sufficiently long and individual sampling times are sufficiently short. Thus, the question becomes more one of feasible frequency rather than total of repeated representative samples. Finally, it should be pointed out in this context that the alternative in situ method using suction cups for extraction of liquid pore water will definitely reduce the local water content significantly and hence alter the flow field, therefore, not allowing for a continuous sampling, particularly in dry soils.

A range of environmental and sampling related characteristics and processes could potentially affect the actual and observed gas-phase isotope signatures and their relation to the local target liquid-phase signatures in space and time. The employed calibration approach provides an advantage in this regard; any constant or temporally variable sampling effects independent of variable conditions diverging from the reference can be assumed to be removed or reflected in the estimated methodological precision. If necessary, systematic effects equally impacting control standard and soil probing (e.g., due to variations of vapor concentration or analyzer temperature) could also be corrected based on assimilated data. A variety of effects could, however, require additional considerations to reduce biases and avoid misinterpretation.

Such effects may be related to sampling and measurement and due to, for example, organics causing spectroscopic interference (West et al., 2010a, 2011; Schultz et al., 2011), vapor extraction causing evaporative surface cooling (Cappa et al., 2003), or variable specific isotopic fractionation associated with transport across a particular porous probing material. Although the latter was found to be negligible in initial headspace experiments comparing SWIP-based versus direct intake sampling (data not shown), such may arise under saturated conditions (Herbstritt et al., 2012) and depending upon concentration gradients across the porous walls, vapor extraction rates, and properties of the probing tube.

More fundamental are potential environmental effects in the soil. Such may include variable liquid-vapor isotopic equilibrium depending on physicochemical states such as chemical (osmotic or matric) potential of water (see e.g., Sofer and Gat, 1972; Horita, 1989; Horita and Wesolowski, 1994; but also Allison, 1987; Rothfuss et al., 2013) or temporary disequilibrium due to water and vapor movement, net phase changes, and isotopic exchange in soils (see Soderberg et al., 2012, and references therein). Note in this context that the relevant rates of liquid-vapor isotopic exchange may depend upon, for example, properties of the geologic material (Hsieh et al., 1998b; Wassenaar et al., 2008), physicochemical states (Ingraham and Criss, 1998), and saturation controlled liquid surface area to volume ratio (Ingraham and
Criss, 1993; Costanza-Robinson and Brusseau, 2002), with implications for the actual resolvability of dynamic liquid pore water signatures. In addition and similar to previous sampling approaches (e.g., Landon et al., 1999; FigueroaJohnson et al., 2007; Wassenaar et al., 2008), the process information may be blurred by unconsidered alteration of liquid soil water isotopic composition itself (e.g., due to interactions with inorganic or organic soil constituents) or unclear contribution of water stored in different compartments of the pore space (e.g., Brooks et al., 2010).

\subsection{Outlook}

The above enumeration of potential effects that may interact and vary depending upon the specific soil properties clarifies that further research into the underlying physical and the sampling related aspects is needed to attain complete confidence in the representativeness of results obtained using the presented or any other, particularly vapor-based pore water isotope sampling approach. While we did not observe obvious systematic impediment to multi-day measurements of control standards or deviations from methodologically similar direct equilibration measurements of soil core samples, such cannot be generally precluded based on the data set presented. Instead, relevant effects may be anticipated to emerge during long-term applications, when more extreme and variable conditions in space and time are encountered, and when the level of "identity" of natural and reference conditions present for this study cannot be practically attained. As such, the introduced monitoring techniques will certainly profit from continued laboratory experimentation, broad and prolonged field application, and further comparison with conventional methods.

Subject to its own peculiarities, the presented approach drastically decreases the expenditure of time, labor, and money for pore water stable isotope monitoring while eliminating a variety of error and uncertainty sources associated with sample collection, transport, storage, and preparation. The ability of minimal-invasive repeated sample generation at a multitude of locations and at an unprecedented rate extends the scope of stable isotope analysis for manifold applications, such as investigations of vertical and lateral subsurface flow and transport processes or plant-soil water interactions. According to the premise that an experimental design should provide the maximum information for the minimum expenditure, the choice of method will thereby depend upon the processes and anticipated conditions at the site under investigation. DDS probes are more expensive than ADS probes in terms of acquisition and maintenance (i.e., demanding additional carrier gas supply and control), but will be required when saturated conditions could be encountered. In contrast, the push-in application strongly reduces acquisition cost and will be particularly useful when spatial variations of soil water isotopic composition are of primary interest, while continuous assessment of 
highly dynamic processes will require permanently installed probes, and a combination of both applications with each other and/or destructive sampling can provide valuable spatiotemporal information.

\section{Conclusions}

This paper introduced a novel system for continual in situ monitoring of pore water stable isotope distributions. The system was technically and operationally implemented to be durable and functional, facilitating automated, minimalinvasive sampling with high frequency, yet limited in cost. Along with a specific on-site calibration approach and basic corrections for instrument bias and liquid-vapor isotopic fractionation, sufficiently accurate and precise inference of normalized liquid pore water isotopic composition was facilitated at sampling intervals of less than four minutes under the conditions encountered. Thereby, the isotopic variability along natural depth profiles was resolved at the measurement scale of ten centimeters. Comparison indicated that the presented in situ approaches may be used interchangeably with each other and with laboratory-based direct equilibration measurements of destructively collected samples. The choice of method will thus depend upon the task and anticipated conditions of sampling. While further research is clearly needed to evaluate and enhance universal reliability and applicability across variable conditions in space and time, the monitoring system has demonstrated capabilities of continual sample generation from a multitude of locations and at an unprecedented rate with minimal disturbance of natural processes. This provides for a powerful tool that can open new avenues towards a detailed quantitative understanding of subsurface water dynamics and fluxes in and out of the soil such as infiltration, recharge, evapotranspiration, and runoff.

Acknowledgements. This work is part of the project "Coupled soil-plant water dynamics - Environmental drivers and species effects" funded by the German Research Foundation (DFG). The authors gratefully thank the technicians, student assistants, and other helpers during preparation and realization of the field experiments, especially Emil Blattmann, Nicolai Dietermann, Benjamin Eisele, Barbara Herbstritt, Lara Kirn, and Lukas Neuhaus.

Edited by: H. Cloke

\section{References}

Aemisegger, F., Sturm, P., Graf, P., Sodemann, H., Pfahl, S., Knohl, A., and Wernli, H.: Measuring variations of $\delta^{18} \mathrm{O}$ and $\delta^{2} \mathrm{H}$ in atmospheric water vapour using two commercial laser-based spectrometers: an instrument characterisation study, Atmos. Meas. Tech., 5, 1491-1511, doi:10.5194/amt-5-1491-2012, 2012.

Aggarwal, P. K., Gat, J. R., and Froehlich, K. F. O. (Eds.): Isotopes in the water cycle: past, present and future of a developing science, Springer, Dordrecht, The Netherlands, 381 pp., 2007.

Allison, G. B.: The relationship between ${ }^{18} \mathrm{O}$ and deuterium in water in sand columns undergoing evaporation, J. Hydrol., 55, 163169, doi:10.1016/0022-1694(82)90127-5, 1982.

Allison, G. B., Barnes, C. J., and Hughes, M. W.: The distribution of deuterium and ${ }^{18} \mathrm{O}$ in dry soils 2. Experimental, J. Hydrol., 64, 377-397, doi:10.1016/0022-1694(83)90078-1, 1983.

Allison, G. B., Colin-Kaczala, C., Filly, A., and Fontes, J. C.: Measurement of isotopic equilibrium between water, water vapour and soil $\mathrm{CO}_{2}$ in arid zone soils, J. Hydrol., 95, 131-141, doi:10.1016/0022-1694(87)90120-x, 1987.

Barnes, C. J. and Allison, G. B.: Tracing of water movement in the unsaturated zone using stable isotopes of hydrogen and oxygen, J. Hydrol., 100, 143-176, doi:10.1016/0022-1694(88)90184-9, 1988.

Berden, G., Peeters, R., and Meijer, G.: Cavity ring-down spectroscopy: Experimental schemes and applications, Int. Rev. Phys. Chem., 19, 565-607, doi:10.1080/014423500750040627, 2000.

Bland, M. J. and Altman, D. G.: Statistical methods for assessing agreement between two methods of clinical measurement, The Lancet, 327, 307-310, doi:10.1016/S0140-6736(86)908378, 1986.

Brand, W. A.: Mass spectrometer hardware for analyzing stable isotope ratios, in: Handbook of stable isotope analytical techniques, edited by: de Groot, P. A., Elsevier, Amsterdam, The Netherlands, 835-856, 2004.

Brooks, J. R., Barnard, H. R., Coulombe, R., and McDonnell, J. J.: Ecohydrologic separation of water between trees and streams in a Mediterranean climate, Nat. Geosci., 3, 100-104, doi:10.1038/Ngeo722, 2010.

Buttle, J. M. and Sami, K.: Recharge processes during snowmelt: An isotopic and hydrometric investigation, Hydrol. Process., 4, 343-360, doi:10.1002/hyp.3360040405, 1990.

Cappa, C. D., Hendricks, M. B., DePaolo, D. J., and Cohen, R. C.: Isotopic fractionation of water during evaporation, J. Geophys. Res., 108, 4525, doi:10.1029/2003jd003597, 2003.

Costanza-Robinson, M. S. and Brusseau, M. L.: Air-water interfacial areas in unsaturated soils: Evaluation of interfacial domains, Water Resour. Res., 38, 1195, doi:10.1029/2001wr000738, 2002.

Craig, H.: Isotopic Variations in Meteoric Waters, Science, 133, 1702-1703, doi:10.1126/science.133.3465.1702, 1961.

Crosson, E. R.: A cavity ring-down analyzer for measuring atmospheric levels of methane, carbon dioxide, and water vapor, Appl. Phys. B: Lasers Opt., 92, 403-408, doi:10.1007/s00340008-3135-y, 2008.

Dansgaard, W.: Stable isotopes in precipitation, Tellus, 16, 436468, doi:10.1111/j.2153-3490.1964.tb00181.x, 1964.

Darling, W. G. and Bath, A. H.: A stable isotope study of recharge processes in the English Chalk, J. Hydrol., 101, 31-46, doi:10.1016/0022-1694(88)90026-1, 1988. 
Dawson, T. E.: Hydraulic lift and water use by plants: implications for water balance, performance and plant-plant interactions, Oecologia, 95, 565-574, doi:10.1007/bf00317442 1993.

Dawson, T. E.: Determining water use by trees and forests from isotopic, energy balance and transpiration analyses: the roles of tree size and hydraulic lift, Tree Physiol., 16, 263-272, doi:10.1093/treephys/16.1-2.263, 1996.

Dawson, T. E. and Ehleringer, J. R.: Streamside trees that do not use stream water, Nature, 350, 335-337, doi:10.1038/350335a0, 1991.

Dincer, T., Al-Mugrin, A., and Zimmermann, U.: Study of the infiltration and recharge through the sand dunes in arid zones with special reference to the stable isotopes and thermonuclear tritium, J. Hydrol., 23, 79-109, doi:10.1016/0022-1694(74)90025$0,1974$.

Ehhalt, D. and Knott, K.: Kinetische Isotopentrennung bei der Verdampfung von Wasser, Tellus, 17, 389-397, doi:10.1111/j.21533490.1965.tb01431.x, 1965.

Ehleringer, J. R. and Dawson, T. E.: Water uptake by plants: perspectives from stable isotope composition, Plant. Cell Environ., 15, 1073-1082, doi:10.1111/j.1365-3040.1992.tb01657.x, 1992.

Figueroa-Johnson, M., Tindall, J., and Friedel, M.: A comparison of ${ }^{18} \mathrm{O} \delta$ composition of water extracted from suction lysimeters, centrifugation, and azeotropic distillation, Water, Air, Soil Pollut., 184, 63-75, doi:10.1007/s11270-007-9399-8, 2007.

Friedman, I., Redfield, A. C., Schoen, B., and Harris, J.: The variation of the deuterium content of natural waters in the hydrologic cycle, Rev. Geophys., 2, 177-224, doi:10.1029/RG002i001p00177, 1964.

Garvelmann, J., Külls, C., and Weiler, M.: A porewater-based stable isotope approach for the investigation of subsurface hydrological processes, Hydrol. Earth Syst. Sci., 16, 631-640, doi:10.5194/hess-16-631-2012, 2012.

Gat, J. R.: Oxygen and hydrogen isotopes in the hydrologic cycle, Annu. Rev. Earth Planet. Sci., 24, 225-262, doi:10.1146/annurev.earth.24.1.225, 1996.

Gazis, C. and Feng, X.: A stable isotope study of soil water: evidence for mixing and preferential flow paths, Geoderma, 119, 97-111, doi:10.1016/s0016-7061(03)00243-x, 2004.

Gröning, M.: Improved water $\delta^{2} \mathrm{H}$ and $\delta^{18} \mathrm{O}$ calibration and calculation of measurement uncertainty using a simple software tool, Rapid Commun. Mass Spectrom., 25, 2711-2720, doi:10.1002/rcm.5074, 2011.

Gupta, P., Noone, D., Galewsky, J., Sweeney, C., and Vaughn, B. H.: Demonstration of high-precision continuous measurements of water vapor isotopologues in laboratory and remote field deployments using wavelength-scanned cavity ring-down spectroscopy (WS-CRDS) technology, Rapid Commun. Mass Spectrom., 23, 2534-2542, doi:10.1002/rcm.4100, 2009.

Hädrich, F. and Stahr, K.: Die Böden des Breisgaus und angrenzender Gebiete, Berichte der Naturforschenden Gesellschaft Freiburg i.Br. 91, 143 pp., 2001.

Helliker, B. and Noone, D.: Novel approaches for monitoring of water vapor isotope ratios: plants, lasers and satellites, in: Isoscapes, edited by: West, J. B., Bowen, G. J., Dawson, T. E., and Tu, K. P., Springer, Dordrecht, The Netherlands, 71-88, 2010.

Herbstritt, B., Gralher, B., and Weiler, M.: Continuous in situ measurements of stable isotopes in liquid water, Water Resour. Res., 48, W03601, doi:10.1029/2011wr011369, 2012.
Horita, J.: Analytical aspects of stable isotopes in brines, Chem. Geol., 79, 107-112, doi:10.1016/0168-9622(89)90013-4, 1989.

Horita, J. and Kendall, C.: Stable isotope analysis of water and aqueous solutions by conventional dual-inlet mass spectrometry, in: Handbook of stable isotope analytical techniques, edited by: de Groot, P. A., Elsevier, Amsterdam, The Netherlands, 1-37, 2004.

Horita, J. and Wesolowski, D. J.: Liquid-vapor fractionation of oxygen and hydrogen isotopes of water from the freezing to the critical temperature, Geochim. Cosmochim. Acta, 58, 3425-3437, doi:10.1016/0016-7037(94)90096-5, 1994.

Hsieh, J. C. C., Chadwick, O. A., Kelly, E. F., and Savin, S. M.: Oxygen isotopic composition of soil water: Quantifying evaporation and transpiration, Geoderma, 82, 269-293, doi:10.1016/s0016-7061(97)00105-5, 1998a.

Hsieh, J. C. C., Savin, S. M., Kelly, E. F., and Chadwick, O. A.: Measurement of soil-water $\mathrm{O}-18$ values by direct equilibration with $\mathrm{CO}_{2}$, Geoderma, 82, 255-268, doi:10.1016/s00167061(97)00104-3, 1998b.

Iannone, R. Q., Romanini, D., Cattani, O., Meijer, H. A. J., and Kerstel, E. R. T.: Water isotope ratio $\left(\delta^{2} \mathrm{H}\right.$ and $\left.\delta^{18} \mathrm{O}\right)$ measurements in atmospheric moisture using an optical feedback cavity enhanced absorption laser spectrometer, J. Geophys. Res., 115, D10111, doi:10.1029/2009jd012895, 2010.

Ingraham, N. L. and Criss, R. E.: Effects of surface area and volume on the rate of isotopic exchange between water and water vapor, J. Geophys. Res.-Atmos., 98, 20547-20553, doi:10.1029/93jd01735, 1993.

Ingraham, N. L. and Criss, R. E.: The effect of vapor pressure on the rate of isotopic exchange between water and water vapor, Chem. Geol., 150, 287-292, doi:10.1016/s0009-2541(98)001090, 1998.

Ingraham, N. L. and Shadel, C.: A comparison of the toluene distillation and vacuum/heat methods for extracting soil water for stable isotopic analysis, J. Hydrol., 140, 371-387, doi:10.1016/0022-1694(92)90249-u, 1992.

Johnson, L. R., Sharp, Z. D., Galewsky, J., Strong, M., Van Pelt, A. D., Dong, F., and Noone, D.: Hydrogen isotope correction for laser instrument measurement bias at low water vapor concentration using conventional isotope analyses: application to measurements from Mauna Loa Observatory, Hawaii, Rapid Commun. Mass Spectrom., 25, 608-616, doi:10.1002/Rcm.4894, 2011.

Kendall, C. and McDonnell, J. J. (Eds.): Isotope tracers in catchment hydrology, Elsevier, Amsterdam, The Netherlands, 839 pp. 1998.

Kerstel, E. and Gianfrani, L.: Advances in laser-based isotope ratio measurements: selected applications, Appl. Phys. B: Lasers Opt., 92, 439-449, doi:10.1007/s00340-008-3128-x, 2008.

Kerstel, E. R. T. and Meijer, H. A. J.: Optical isotope ratio measurements in hydrology, in: Isotopes in the Water Cycle, edited by: Aggarwal, P. K., Gat, J. R., and Froehlich, K. F. O., Springer, Dordrecht, The Netherlands, 109-123, 2005.

Koehler, G., Wassenaar, L. I., and Hendry, M. J.: An Automated Technique for Measuring $\delta \mathrm{D}$ and $\delta^{18} \mathrm{O}$ Values of Porewater by Direct $\mathrm{CO}_{2}$ and $\mathrm{H}_{2}$ Equilibration, Anal. Chem., 72, 5659-5664, doi:10.1021/ac000498n, 2000. 
Landon, M. K., Delin, G. N., Komor, S. C., and Regan, C. P.: Comparison of the stable-isotopic composition of soil water collected from suction lysimeters, wick samplers, and cores in a sandy unsaturated zone, J. Hydrol., 224, 45-54, doi:10.1016/S00221694(99)00120-1, 1999.

Laudon, H., Seibert, J., Köhler, S., and Bishop, K.: Hydrological flow paths during snowmelt: Congruence between hydrometric measurements and oxygen 18 in meltwater, soil water, and runoff, Water Resour. Res., 40, W03102, doi:10.1029/2003wr002455, 2004.

Majoube, M.: Fractionnement en oxygène-18 et en deutérium entre l'eau et sa vapeur, J. Chim. Phys., 68, 1423-1436, 1971.

Mark, J. E.: Polymer data handbook, Oxford University Press, New York, USA, 2009.

McDonnell, J. J.: A Rationale for Old Water Discharge Through Macropores in a Steep, Humid Catchment, Water Resour. Res., 26, 2821-2832, doi:10.1029/WR026i011p02821, 1990.

Munksgaard, N. C., Wurster, C. M., and Bird, M. I.: Continuous analysis of $\delta^{18} \mathrm{O}$ and $\delta \mathrm{D}$ values of water by diffusion sampling cavity ring-down spectrometry: a novel sampling device for unattended field monitoring of precipitation, ground and surface waters, Rapid Commun. Mass Spectrom., 25, 3706-3712, doi:10.1002/rcm.5282, 2011.

Munksgaard, N. C., Wurster, C. M., Bass, A., and Bird, M. I.: Extreme short-term stable isotope variability revealed by continuous rainwater analysis, Hydrol. Process., 26, 3630-3634, doi:10.1002/hyp.9505, 2012a.

Munksgaard, N. C., Wurster, C. M., Bass, A., Zagorskis, I., and Bird, M. I.: First continuous shipboard $\delta^{18} \mathrm{O}$ and $\delta \mathrm{D}$ measurements in sea water by diffusion sampling - cavity ring-down spectrometry, Environ. Chem. Lett., 10, 301-307, doi:10.1007/s10311-012-0371-5, 2012b.

Picarro L2120-i $\delta \mathrm{D} / \delta^{18} \mathrm{O}$ isotopic water analyzer: http: //www.picarro.com/sites/default/files/L2120-i\%20Datasheet.pdf (last access: 10 April 2013), 2012.

Rothfuss, Y., Biron, P., Braud, I., Canale, L., Durand, J. L., Gaudet, J. P., Richard, P., Vauclin, M., and Bariac, T.: Partitioning evapotranspiration fluxes into soil evaporation and plant transpiration using water stable isotopes under controlled conditions, Hydrol. Process., 24, 3177-3194, doi:10.1002/Hyp.7743, 2010.

Rothfuss, Y., Vereecken, H., and Brüggemann, N.: Monitoring water stable isotopic composition in soils using gas-permeable tubing and infrared laser absorption spectroscopy, Water Resour. Res., 49, 3747-3755, doi:10.1002/wrcr.20311, 2013.

Saxena, R.: Seasonal variations of oxygen-18 in soil moisture and estimation of recharge in esker and moraine formations, Nord. Hydrol., 15, 235-242, doi:10.2166/nh.1984.020, 1984.

Schmidt, M., Maseyk, K., Lett, C., Biron, P., Richard, P., Bariac, T., and Seibt, U.: Concentration effects on laser-based $\delta^{18} \mathrm{O}$ and $\delta^{2} \mathrm{H}$ measurements and implications for the calibration of vapour measurements with liquid standards, Rapid Commun. Mass Spectrom., 24, 3553-3561, doi:10.1002/rcm.4813, 2010.

Schultz, N. M., Griffis, T. J., Lee, X., and Baker, J. M.: Identification and correction of spectral contamination in ${ }^{2} \mathrm{H} /{ }^{1} \mathrm{H}$ and ${ }^{18} \mathrm{O} /{ }^{16} \mathrm{O}$ measured in leaf, stem, and soil water, Rapid Commun. Mass Spectrom., 25, 3360-3368, doi:10.1002/rcm.5236, 2011.
Schulze, E. D., Caldwell, M. M., Canadell, J., Mooney, H. A., Jackson, R. B., Parson, D., Scholes, R., Sala, O. E., and Trimborn, P.: Downward flux of water through roots (i.e. inverse hydraulic lift) in dry Kalahari sands, Oecologia, 115, 460-462, doi:10.1007/s004420050541, 1998.

Sklash, M. G. and Farvolden, R. N.: The role of groundwater in storm runoff, J. Hydrol., 43, 45-65, doi:10.1016/00221694(79)90164-1, 1979.

Soderberg, K., Good, S. P., Wang, L., and Caylor, K.: Stable isotopes of water vapor in the vadose zone: A review of measurement and modeling techniques, Vadose Zone J., 11, No. 3, doi:10.2136/vzj2011.0165, 2012.

Sofer, Z. and Gat, J.: Activities and concentrations of oxygen18 in concentrated aqueous salt solutions: analytical and geophysical implications, Earth Planet. Sci. Lett., 15, 232-238, doi:10.1016/0012-821X(72)90168-9, 1972.

Stewart, M. K. and McDonnell, J. J.: Modeling base flow soil water residence times from deuterium concentrations, Water Resour. Res., 27, 2681-2693, doi:10.1029/91wr01569, 1991.

Sturm, P. and Knohl, A.: Water vapor $\delta^{2} \mathrm{H}$ and $\delta^{18} \mathrm{O}$ measurements using off-axis integrated cavity output spectroscopy, Atmos. Meas. Tech., 3, 67-77, doi:10.5194/amt-3-67-2010, 2010.

Thoma, G., Esser, N., Sonntag, C., Weiss, W., Rudolph, J., and Leveque, P.: New technique of in-situ soil moisture sampling for environmental isotope analysis applied at Pilat sand dune near Bordeaux, Isot. Hydrol. Proc. Symp., Neuherberg, 1979, 753-766, 1979.

Thorburn, P., Walker, G., and Hatton, T.: Are river red gums taking water from soil, groundwater or streams, Catchments of green: a national conference on vegetation \& water management, conference proceedings-volume B, 63-68, 1992.

Vitvar, T., Aggarwal, P. K., and McDonnell, J. J.: A review of isotope applications in catchment hydrology, in: Isotopes in the Water Cycle, edited by: Aggarwal, P. K., Gat, J. R., and Froehlich, K. F. O., Springer, Dordrecht, The Netherlands, 151-169, 2005.

Walker, C. D. and Richardson, S. B.: The use of stable isotopes of water in characterising the source of water in vegetation, Chem. Geol., 94, 145-158, doi:10.1016/0168-9622(91)90007-j, 1991.

Walker, G. R., Hughes, M. W., Allison, G. B., and Barnes, C. J.: The movement of isotopes of water during evaporation from a bare soil surface, J. Hydrol., 97, 181-197, doi:10.1016/00221694(88)90114-x, 1988.

Walker, G. R., Woods, P. H., and Allison, G. B.: Interlaboratory comparison of methods to determine the stable isotope composition of soil water, Chem. Geol., 111, 297-306, doi:10.1016/0009-2541(94)90096-5, 1994.

Wang, X. F. and Yakir, D.: Using stable isotopes of water in evapotranspiration studies, Hydrol. Process., 14, 14071421, doi:10.1002/1099-1085(20000615)14:8<1407::aidhyp992>3.0.co;2-k, 2000.

Wassenaar, L. I., Hendry, M. J., Chostner, V. L., and Lis, G. P.: High resolution pore water $\delta^{2} \mathrm{H}$ and $\delta^{18} \mathrm{O}$ measurements by $_{2} \mathrm{O}_{\text {(liquid) }}-\mathrm{H}_{2} \mathrm{O}_{\text {(vapor) }}$ equilibration laser spectroscopy, Environ. Sci. Technol., 42, 9262-9267, doi:10.1021/Es802065s, 2008. 
Wels, C., Cornett, R. J., and Lazerte, B. D.: Hydrograph separation: A comparison of geochemical and isotopic tracers, J. Hydrol., 122, 253-274, doi:10.1016/0022-1694(91)90181-G, 1991.

West, A. G., Patrickson, S. J., and Ehleringer, J. R.: Water extraction times for plant and soil materials used in stable isotope analysis, Rapid Commun. Mass Spectrom., 20, 1317-1321, doi:10.1002/rcm.2456, 2006.

West, A. G., Goldsmith, G. R., Brooks, P. D., and Dawson, T. E.: Discrepancies between isotope ratio infrared spectroscopy and isotope ratio mass spectrometry for the stable isotope analysis of plant and soil waters, Rapid Commun. Mass Spectrom., 24, 1948-1954, doi:10.1002/rcm.4597, 2010a.

West, J. B., Bowen, G. J., Dawson, T. E., and Tu, K. P. (Eds.): Isoscapes: understanding movement, pattern, and process on Earth through isotope mapping, Springer, Dordrecht, The Netherlands, 2010b.

West, A. G., Goldsmith, G. R., Matimati, I., and Dawson, T. E.: Spectral analysis software improves confidence in plant and soil water stable isotope analyses performed by isotope ratio infrared spectroscopy (IRIS), Rapid Commun. Mass Spectrom., 25, 2268-2274, doi:10.1002/rcm.5126, 2011.
White, J. W. C., Cook, E. R., Lawrence, J. R., and Wallace S, B.: The D/H ratios of sap in trees: Implications for water sources and tree ring D/H ratios, Geochim. Cosmochim. Acta, 49, 237-246, doi:10.1016/0016-7037(85)90207-8, 1985.

Yakir, D. and Sternberg, L. D. S. L.: The use of stable isotopes to study ecosystem gas exchange, Oecologia, 123, 297-311, doi:10.1007/s004420051016, 2000.

Yepez, E. A., Huxman, T. E., Ignace, D. D., English, N. B., Weltzin, J. F., Castellanos, A. E., and Williams, D. G.: Dynamics of transpiration and evaporation following a moisture pulse in semiarid grassland: A chamber-based isotope method for partitioning flux components, Agric. For. Meteorol., 132, 359-376, doi:10.1016/j.agrformet.2005.09.006, 2005.

Zimmermann, U., Ehhalt, D., and Münnich, K. O.: Soil water movement and evapotranspiration: changes in the isotopic composition of the water, Proc. Symp. Isot. Hydrol., Vienna, Austria, 1967, 567-584, 1967. 